University of Wollongong

Research Online

Faculty of Social Sciences - Papers (Archive) Faculty of Arts, Social Sciences \& Humanities

2018

A qualitative exploration of Thai alcohol policy in regulating availability and access

\author{
Ratchakorn Kaewpramkusol \\ University of Wollongong, rk956@uowmail.edu.au \\ Kate Senior \\ University of Wollongong, ksenior@uow.edu.au \\ Richard D. Chenhall \\ University of Melbourne \\ Sutham Nanthamongkolchai \\ Mahidol University \\ Surasak Chaiyasong \\ Mahasarakham University
}

Follow this and additional works at: https://ro.uow.edu.au/sspapers

Part of the Education Commons, and the Social and Behavioral Sciences Commons

Research Online is the open access institutional repository for the University of Wollongong. For further information contact the UOW Library: research-pubs@uow.edu.au 


\title{
A qualitative exploration of Thai alcohol policy in regulating availability and access
}

\author{
Abstract \\ Background: Despite abundant alcohol control regulations and measures in Thailand, prevalence of \\ alcohol consumption has been relatively steady for the past decade and alcohol-related harm remains \\ high. This study aims to explore, through the perspectives of key public health stakeholders, the current \\ performance of regulations controlling alcohol availability and access, and the future directions for the \\ implementation of Thai alcohol policy. Methods: Semi-structured interviews were conducted with public \\ health stakeholders from three sectors; the government, academia and civil society. Their perceptions \\ about the current alcohol situation, gaps in the current policies, and future directions of alcohol policy \\ were discussed. Audio data were transcribed verbatim, systematically coded and analysed. Results: The \\ three key concerning issues were physical availability, economic availability and commercial access, \\ which referred to outlet density, taxation and pricing, and compliance to stipulated regulations, \\ respectively. First, Thailand failed to control the number of alcohol outlets. The availability problem was \\ exacerbated by the increased numbers of liquor licences issued, without delineating the need for the \\ outlets. Second, alcohol tax rates, albeit occasionally adjusted, are disproportionate to the economic \\ dynamic, and there is yet a minimum pricing. Finally, compliance to age and time restrictions was \\ challenging. Conclusions: The lack of robustness of enforcement and disintegration of government \\ agencies in regulating availability and access hampers effectiveness of alcohol policy. Comprehensive \\ regulations for the control of availability of and access to alcohol are required to strengthen alcohol \\ policy. Consistent monitoring and surveillance of the compliances are recommended to prevent \\ significant effects of the regulations diminish over time.

\section{Disciplines} \\ Education | Social and Behavioral Sciences

\section{Publication Details} \\ Kaewpramkusol, R., Senior, K., Chenhall, R., Nanthamongkolchai, S. \& Chaiyasong, S. (2018). A qualitative \\ exploration of Thai alcohol policy in regulating availability and access. International Journal of Drug \\ Policy, 58 1-8.
}


A qualitative exploration of thai alcohol policy in regulating availability and access

\section{Authors:}

Ratchakorn Kaewpramkusol $^{\mathrm{a}, \mathrm{b}, *}$, Kate Senior ${ }^{\mathrm{a}}$, Richard Chenhall ${ }^{\mathrm{c}}$, Sutham Nanthamongkolchai $^{d}$, Surasak Chaiyasong ${ }^{e, f}$,

${ }^{\text {a } S c h o o l ~ o f ~ H e a l t h ~ a n d ~ S o c i e t y, ~ F a c u l t y ~ o f ~ S o c i a l ~ S c i e n c e s, ~ U n i v e r s i t y ~ o f ~ W o l l o n g o n g, ~}$ New South Wales, 2522, Australia

${ }^{\mathrm{b}}$ Global Health Division, Office of the Permanent Secretary, Ministry of Public Health, Nonthaburi, 11000, Thailand

${ }^{c}$ Melbourne School of Population and Global Health, The University of Melbourne, Victoria, 3010, Australia

${ }^{\mathrm{d} D e p a r t m e n t ~ o f ~ F a m i l y ~ H e a l t h, ~ F a c u l t y ~ o f ~ P u b l i c ~ H e a l t h, ~ M a h i d o l ~ U n i v e r s i t y, ~ B a n g k o k, ~}$ 10400, Thailand

${ }^{\text {e}}$ Social Pharmacy Research Unit, Faculty of Pharmacy, Mahasarakham University, Maha Sarakham, 44150, Thailand

${ }^{\mathrm{f}}$ International Health Policy Program, Ministry of Public Health, Nonthaburi, 11000, Thailand

*Corresponding author: Ratchakorn Kaewpramkusol

E-mail: rk956@uowmail.edu.au 


\section{Abstract \\ Background}

Despite abundant alcohol control regulations and measures in Thailand, prevalence of alcohol consumption has been relatively steady for the past decade and alcohol-related harm remains high. This study aims to explore, through the perspectives of key public health stakeholders, the current performance of regulations controlling alcohol availability and access, and the future directions for the implementation of Thai alcohol policy.

\section{Methods}

Semi-structured interviews were conducted with public health stakeholders from three sectors; the government, academia and civil society. Their perceptions about the current alcohol situation, gaps in the current policies, and future directions of alcohol policy were discussed. Audio data were transcribed verbatim, systematically coded and analysed.

\section{Results}

The three key concerning issues were physical availability, economic availability and commercial access, which referred to outlet density, taxation and pricing, and compliance to stipulated regulations, respectively. First, Thailand failed to control the number of alcohol outlets. The availability problem was exacerbated by the increased numbers of liquor licences issued, without delineating the need for the outlets. Second, alcohol tax rates, albeit occasionally adjusted, are disproportionate to the economic dynamic, and there is yet a minimum pricing. Finally, compliance to age and time restrictions was challenging.

\section{Conclusions}

The lack of robustness of enforcement and disintegration of government agencies in regulating availability and access hampers effectiveness of alcohol policy. Comprehensive regulations for the control of availability of and access to alcohol are required to strengthen 
alcohol policy. Consistent monitoring and surveillance of the compliances are recommended to prevent significant effects of the regulations diminish over time.

\section{Keywords}

Qualitative; Semi-structured Interview; Availability; Access; Policy; Enforcement; Alcohol;

Thailand

\section{Introduction:}

Harmful use of alcohol is a causal factor for intentional and unintentional injuries, and contributes to more than 200 alcohol-related health conditions, substantial avoidable disease burden and premature deaths worldwide (World Health Organization, 2014). The harmful use could also lead to criminal liabilities, especially among adolescents and young adults (Wicki, Kuntsche, \& Gmel, 2010). Recognising the close links between harmful use of alcohol and socioeconomic development, the World Health Organization (WHO)'s Global strategy to reduce the harmful use of alcohol was endorsed by its member states in 2010 (World Health Organization, 2010). Following the endorsement, several countries have adopted appropriate and feasible evidenced-based alcohol policies and recommended legislative options to address these public health problems (World Health Organization, 2011). Among the ten recommended areas for policy options and interventions, two areas are relevant to availability of and access to alcoholic beverages; namely physical availability of alcohol and alcohol pricing policies. These interventions and policy measures to restrict availability and access are designed to help reduce consumption of and exposure to alcohol, hence leading to reductions in alcohol-related harm (World Health Organization, 2011), including alcoholrelated hospital admissions (Callaghan, Sanches, \& Gatley, 2013; Callaghan, Sanches, Gatley, \& Cunningham, 2013) and deaths (Callaghan, Sanches, Gatley, \& Stockwell, 2014). 
First, the restrictions of alcohol availability and access have been found to be associated with many adverse outcomes among a variety of population, especially young people, such as increased risk of alcohol consumption (Rowland et al., 2014), binge drinking (Ahern, Margerison-Zilko, Hubbard, \& Galea, 2013), underage drinking, interpersonal violence, and increased alcohol-related hospital admission rates (World Health Organization, 2011). Young people, especially the underage, who reside in high outlet density neighbourhoods have increased risk of early drinking initiation, which partly due to their limited mobility (Chen, Grube, \& Gruenewald, 2010). Social implications are also present in the neighbourhoods with high alcohol outlet density. Mounting evidence supports the relationship between the amount of alcohol consumed and violent behaviour among a variety of populations (Duke, Giancola, Morris, Holt, \& Gunn, 2011). Because of the unique characteristics of alcohol outlets or their density, they not only attract, but are likely to influence both violent and nonviolent crimes (Grubesic, Pridemore, Williams, \& Philip-Tabb, 2013; Toomey et al., 2012). Besides restricting the supply of alcohol, the demand of alcohol can also be regulated by establishing a barrier to commercial access to alcohol such as setting an appropriate minimum age for alcohol purchase or consumption. The specified minimum age could increase difficulties for sales to or consumption by young people (World Health Organization, 2010). To differentiate between the restrictions of supply and demand of alcohol, the term 'commercial access' will be used in this study to refer to the control of the ease to obtaining alcohol through purchases.

Second, pricing policies are used to reduce affordability of alcoholic beverages through pricing and taxation to influence levels of consumption (World Health Organization, 2011). In this study, the alcohol pricing and taxation are collectively referred to as 'economic availability' because of their apparent relevance to the availability and access to alcohol. Two 
evidence-based principals about alcohol pricing are (i) the higher the prices of alcoholic beverages, the greater the reduction in consumption and (ii) the greater the reduction in consumption, the lower the level of alcohol-related harm (Alexander C. Wagenaar, Salois, \& Komro, 2009; World Health Organization, 2011). Systematic review of the effectiveness of price-based alcohol policy interventions, such as minimum unit pricing, illustrates that alcohol pricing could reduce alcohol consumption and so alcohol-related morbidity and mortality (Boniface, Scannell, \& Marlow, 2017). The increased alcohol prices could lower levels of youth drinking through its effect on potential reduction of adult harmful drinking (Xuan et al., 2013). Not only tax burden and increased prices of alcoholic beverages could reduce health inequalities across diverse income groups (Meier et al., 2016), they also could lower availability of alcoholic beverages, especially among heavy drinkers (Vandenberg \& Sharma, 2016). Currently, Thailand is using alcohol taxation system called One-Plus-One which was introduced since September 2017. The system combines the two major taxation methods, ad valorem taxation and specific taxation, when alcoholic beverages are taxed. Ad valorem taxation calculates the excise tax based on the value of alcoholic beverages sold, while specific tax is calculated based on the volume of pure alcohol in a beverage (Bundit Sornpaisarn, Shield, Österberg, \& Rehm, 2017). Previously, Two-Chosen-One (2C1) system was used to excise alcohol where only the higher of the two methods was applied.

Along with the supporting evidence of the effectiveness in the availability and access control to reduce alcohol consumption in many high-income countries, the alcohol research in the low- and middle-income countries is growing to establish evidence-based alcohol policies (World Health Organization, 2014). For Thailand, Alcoholic Beverage Control Act B.E. 2551 (the Act) was enacted in 2008, aiming to discourage drinking among current drinkers and prevent drinking initiation among youth so as to reduce risks of alcohol-related harm (Royal 
Thai Government Gazette, 2008). Since then, an extensive range of these alcohol control regulations and measures has been developed. Despite this, the prevalence of alcohol consumption has been steady at $30-33 \%$ in the Thai population aged 15 and older $\left(15^{+}\right)$for the past decade (National Statistical Office, 2015). At 7.2 litres of pure alcohol, Thailand's alcohol per capita consumption in 15+ is the fourth highest in Asia and the highest in WHO South-East Asia region (World Health Organization, 2014). The global average is at 6.2 litres of pure alcohol per year. Moreover, albeit high abstention and low unrecorded alcohol consumption rates in Thailand, its alcohol-related harm is comparatively greater than many countries with higher per capita consumption. In 2010, Thailand's prevalence of alcohol use disorders is twice the average prevalence in WHO South-East Asia region and its alcoholattributable deaths was the highest (World Health Organization, 2014). The alcohol use among Thai youth reportedly leads to increased risks of drink-driving, violence, injuries, acute health problems, and unsafe sexual behaviours as well as increased tendency to other unhealthy behaviours such as smoking, prescription drug misuse and illicit substance use (Assanangkornchai, Mukthong, \& Intanont, 2009; Chaveepojnkamjorn \& Pichainarong, 2011).

Given that Thailand has abundant and various alcohol control regulations and policy options, a discourse of the performance of Thai alcohol control policy should be initiated to identify gaps for future improvements of measures regulating availability and access. Moreover, as alcohol control policy involves many regulations across different sectors, such as the public health, commerce, social development, and law enforcement agencies, the interactions between these agencies in the implementation of the alcohol policy should also be determined. Since public health sector is the main actor in the development and implementation of alcohol policy, this study aims to explore, through the perspectives of key 
public health stakeholders, the current performance of regulations controlling alcohol availability and access and the future directions of Thai alcohol policy. The exploration of the gaps in regulating alcohol availability and access could provide important insight for future alcohol policy dialogue and development.

\section{Methods:}

Semi-structured interviews were conducted between May and August 2016. The respondents were key stakeholders who have involved in the alcohol policy process and/or have been actively involved in alcohol research and policy development. The stakeholders were from three sectors; the government (policymaker), academia and civil society. The three interconnected sectors simultaneously strengthen capacity in three interrelated areas, namely political involvement (the government), creation of knowledge (academia) and social movement (civil society) (Thaksaphon Thamarangsi, 2009). These three sectors are collectively called the "triangle that moves the mountain" as proposed by a well-known medical, public health and social scholar in Thailand, Professor Prawase Wasi. Pragmatic purposive sampling through policy networks and snowball referrals were used. List of the members of the National Alcohol Policy Commission as appointed by the Alcohol Control Act was used for initial sample selection. The members of the Commission consisted of representatives from government agencies, non-governmental organisations, and persons whose knowledge, competence and experience pertaining to the fields of either social science, law or information and communication technology. A summary of respondents' areas of work and/or expertise is presented in Table 1. The ethical approvals were granted by the Human Research Ethics committees of the University of Wollongong (HE15/480) and of Mahidol University in Thailand (MUPH 2016-034). 
Table 1: Respondents' Areas of Work and/or Expertise

\begin{tabular}{|l|c|l|}
\hline \multicolumn{1}{|c|}{ Category } & ID Number & \multicolumn{1}{|c|}{ Organisation's Work and/or Expertise } \\
\hline Government & G1 & Alcohol policy \\
\cline { 2 - 3 } & G2 & Alcohol policy and enforcement under G1 \\
\cline { 2 - 3 } & G3 & Government-research unit hybrid organisation \\
\hline Academia & A1 & Alcohol industry's behaviour \\
\cline { 2 - 3 } & A2 & Media communication of alcohol industry \\
\cline { 2 - 3 } & A3 & Alcohol research in Thailand and health economics \\
\cline { 2 - 3 } & A4 & Alcohol research and international collaboration \\
\hline Civil Society & S1 & Drunk-driving watchdog \\
\cline { 2 - 3 } & S2 & Alcohol information and awareness in Thailand \\
\cline { 2 - 3 } & S3 & Alcohol-related harm watchdog \\
\hline
\end{tabular}

\section{Data Collection}

The semi-structured interviews were conducted face-to-face, facilitated by an interview topic guide to elicit information from respondents. Each interview had a duration of 30 to 60 minutes. The interview topic guide contained open-ended questions asking the respondents about their perceptions and perspectives of the current alcohol use in Thailand, the roles of their organisation, gaps in the current policy and the future directions of alcohol policy. The respondents had been provided with the topic guide in advance. An information statement and a consent form were provided to the respondents were in both English and Thai to ensure that all respondents were well informed. The informed consent was received prior to commencement of the interview. To maintain confidentiality, each respondent was assigned an ID number.

\section{Data Analysis}

Audio data were transcribed verbatim, systematically coded and analysed. First, the recorded discussions were transcribed verbatim. Second, the transcribed data were read, re-read, and 
coded separately by two researchers (RK and SN). Thematic content analysis was used to identify key themes concerning effectiveness and efficiency of policy measures regulating alcohol availability and access in Thailand. The data were continually coded and refined into categories. Notes were taken throughout the process of analysis. Third, the emerging themes, categories and concepts were discussed among study team. Finally, constant comparative approach was used to refine the analysis, comparing analysed data for similarities and differences, until data reached saturation point.

\section{Results:}

The results of the study were classified into two major alcohol control strategies; the control of supply and demand. The control of supply described how alcohol control measures regulate economic availability and physical availability. The control of demand described how the measures regulate commercial access to alcoholic beverages.

\section{Economic Availability}

The Thai government's main focus on alcohol control has been the control of supply side. The respondents from the government sector noted that not only controlling supply sides would lower purchasing power, but it could also potentially influence drinkers' attitudes through the restriction of access to alcohol. However, they also acknowledged that the control of demand would be relatively ineffective on its own, the efficacy may increase as a part of the combination of both demand and supply control strategies.

\section{Alcohol Pricing}

The affordability of alcoholic beverages was debatable in Thailand. The respondents from all three sectors considered that alcohol prices were too low and the prices should be manipulated through alcohol pricing and taxation mechanisms to increase prices, hence 
reducing the alcohol affordability. They also suggested that a policy option to introduce minimum alcohol pricing could be an appropriate solution to lower the affordability.

“...we don’t have minimum alcohol pricing. Alcohol is so cheap that youth can access it.” - S2

“...alcoholic beverages are not ordinary goods like milk or orange juice. For ordinary goods, we control their prices, to not let them be too expensive. But alcohol prices shouldn’t be too cheap.”- G2

\section{Alcohol Taxation}

Further, the respondents, especially those from the civil society sector, highlighted that the previous incremental adjustments of alcohol tax rates have been inconsistent and disproportionate to the current economic situation such as the inflation rate. The decisions to adjust tax rates relied solely on the Ministry of Finance (the Excise Department). It was unclear whether external inputs from other government agencies or non-governmental organisations have ever been considered for any previous alcohol tax adjustments.

\footnotetext{
Alcohol excise tax should increase more frequently... and the increase should be appropriate (in proportion to inflation rate), so the alcohol prices are not too low. We've submitted a proposal (on tax increase) to the Excise Department, but nothing has changed yet.” - S2
}

The current 2C1 taxation system, though, was claimed by the Thai government to be efficient because it has allowed the government to selectively collect higher tax revenue from either 
ad valorem or specific tax. However, the current tax rates were varied across different types of alcohol and the system were deemed as posing preferential treatment over particular alcoholic products. Therefore, the government reportedly expected to consider an alternative system to improve its alcohol taxation system. The proposed alternative system would be called One-Plus-One. The aim was to impartially excise all types of alcoholic beverages, because this system would excise all alcoholic beverages based on both volume and strength of alcohol.

“Two-Chosen-One is good, but I think It'd be better to have OnePlus-One, ad valorem and specific tax together. If we used One-PlusOne, all beverages would pay for both. (Combination taxation) will be harder (for alcohol industry) to avoid paying higher tax.” - G3

\section{Physical Availability}

\section{Alcohol Outlet}

The restriction of physical availability of alcohol outlets was extensively discussed by the respondents from all three sectors. The restriction measures included zoning of outlets, outlet density control and liquor licensing. First, the respondent from a civil society noted that the recently introduced alcohol-free zoning around tertiary educational institutions was relatively vague, and questioned its effectiveness which was yet to be assessed. The measure was criticised to be too flexible, because it allowed the existing alcohol outlets to continue operating in the zoning area. The respondent strongly advocated for the relocation of existing alcohol outlets in the alcohol-free zone within a specified timeframe. 
“(The zoning) allows the existing outlets to stay in the zone. The new measure is only for the new outlets. But I think they should (tell) the existing outlets to relocate within 3-5 years.” - S3

Other respondents from civil society sector also emphasised the rising number of licensed alcohol outlets in Thailand which they considered to be noticeably higher than many other countries. They added that the ease of obtaining alcoholic beverages was further exacerbated by the short distance to the outlets and the widespread availability of unlicensed outlets. The respondents also criticised the failure to include a provision about the restriction of alcohol outlet density in the Act. A respondent from a civil society organisation suggested that alcoholic beverages should be sold only in specified stores (bottle shops) to effectively decrease the number of alcohol outlets.

“...there're more than 600,000 licensed outlets and about 2-3 times the number of unlicensed outlets. We sell alcohol everywhere even at (small street food stalls). Alcohol shouldn't be sold in the same stores as other ordinary goods. We should make it clear that what (kind of) stores can sell alcohol...”- S2

Additionally, the respondents emphasised that the absence of the roles of local community's involvement in the control of number of alcohol outlets, such as public engagement and hearing for liquor store establishment in the neighbourhoods. They also suggested that the local community's involvement could potentially strengthen and mitigate the effects of availability regulations that lead to reduced social problems locally and, theoretically, nationally. 


\section{Licensing}

Another issue raised by the respondents that potentially dictate the number of alcohol outlets was liquor licensing. The respondents concerned about the high number of licensed and unlicensed alcohol outlets in Thailand. They described that despite the compulsory requirement to obtain a liquor licence for alcohol sale, the acquisition of liquor licence was very simple and inexpensive. The licensing was not based on population density nor limited by any specified quota, leading to explosion of alcohol outlets across the country.

"If the government is serious about controlling the retail outlets, they should limit the number of licences. The government also needs to increase the licensing fee and introduce quota based on the population density in the neighbourhoods.”-A1

A government respondent noted that the contradiction between the fields of work of different government agencies (public health versus finance) could undermine the control of alcohol physical availability and raised a question whether public health agency should be the licensing authority instead of the Excise Department.

"If the Ministry of Public Health had got the authority to control alcohol sales (through licensing), we would separate alcoholic beverages to be sold in separate stores. We don't want young people to think that alcohol is like any other ordinary goods. However, the responsible authority (for licensing) is the Excise Department. (Revenue generation) is a part of their (organisation's) Key 
Performance Indicators, which undermines our work (Ministry of Public Health's) to reduce alcohol-related impacts. This is the dilemma.”-G2

The respondents from both civil society and academia sectors, too, noted the contradicting fields of work between different government administrative bodies. They commented that the public health sector was working towards lowering adverse consequences of alcohol consumption through various access restrictions such as age, time and place restrictions. At the other end, the economic sector was working towards generating revenue and delivering excellent services to businesses such as easing the process to obtain liquor licences, hence undermining the public health sector's effort. The respondents blamed the different sets of law and different sets of key performance indicators they were obligated to as the cause of such disintegration. Nonetheless, it is worth noting that various government agencies have reportedly started to display their intentions to cooperatively manage alcohol-related problems in Thailand.

“(The Excise Department) doesn’t take public health perspective into consideration when issues liquor licences. It only aims to increase the number of liquor licence applications submitted. - S3

"Revenue (from liquor licensing fee) is something they (the Excise Department) focus on. (one of) their KPIs is to provide efficient registration service to the businesses” - A3

\section{Commercial Access}


Commercial access to alcoholic beverages was also one of the factors discussed to be influential in the drinking phenomenon in Thailand. The respondents considered the ease of purchasing alcoholic beverages to be a significant and persistent concern. Despite stipulated regulations specifying the minimum legal age and time restrictions for alcohol sales, the compliance was questionable. A respondent from a civil society organisation raised a concern about compliance to time restriction for alcohol sales across different types of stores and referred to his personal experience in which the report of such violation to the responsible authority yielded unsatisfactory reactions. Respondents also stressed that the high number of licensed and unlicensed outlets, could create a difficulty for the government officials to monitor the compliance to the regulations. According to a respondent from government sector, the lax monitoring and surveillance could be due to insufficiently allocated resources.

“...the law permits alcohol sales in only two time periods, 11:0014:00 and 17:00-24:00. Convenience stores may cooperate, but grocery stores sell alcohol at any time they want. When we report it to the law enforcement, they think we're too punctilious” - S1

“...there are more than 600,000 licensed alcohol outlets and probably about the same number for unlicensed outlets. We don’t have enough human resources to conduct monitoring and surveillance.”- G2

\section{Implementation and Enforcement}

Moreover, the criticisms of disintegration of fields of work between government agencies and the insufficiently allocated resources in regulating availability and access have led to the discussions about the amount of regulations, the robustness of enforcement, and the 
credibility of alcohol control in Thailand. Respondents from civil society and academia sectors commented that while the government continued to introduce new alcohol control measures, the enforcement was deficient. They noted that many of the alcohol-related measures have not been fully implemented, because they were copious and getting complicated.

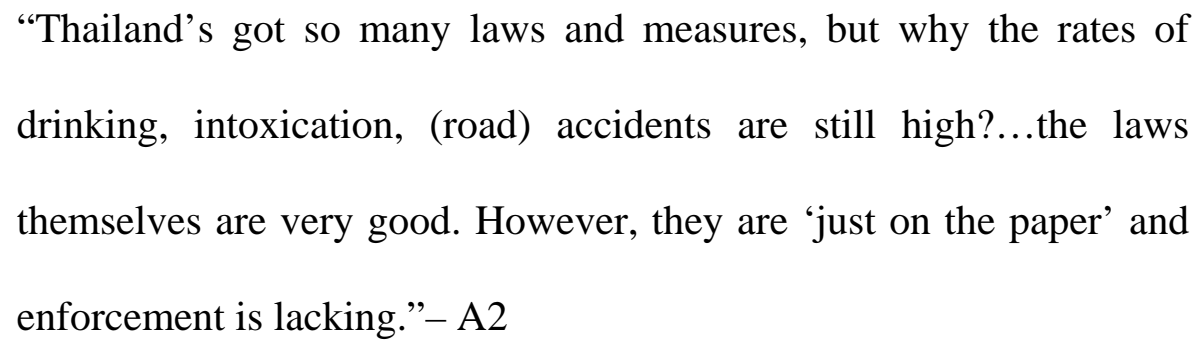

The robustness of enforcement was a subject of debate among the respondents who regarded strenuous enforcement to be a critical tool in changing drinking attitude and behaviour. The respondents asserted that the deficient supports for human and financial resources led to the lacked robustness of enforcement. A respondent from government sector revealed that the increasing amount of alcohol control measures was disproportionate to the present capacity of human capital.

\footnotetext{
“Thailand's got so many regulations and policies, however the enforcement and implementation are not rigorous enough. First, there's a lack of orders from the managing superiors. Second, human and financial resources and necessary equipment (breathalyser) are not adequate. Third, the law enforcement doesn't really have enough literacy (of these many alcohol measures)" - A4
} 
The deficient resources have admittedly impacted on the quality of implementation of stipulated measures performed by responsible unit of public health agency. Such deficiency could be due to the bureaucracies of governmental hierarchy. The executive government unit itself has seemingly realised that the allocated budget did not meet the number of additional tasks placed upon relevant government agencies, but explained that adjustment of human and financial resources would need to increase gradually over time.

“A small division (government agency at Ministry of Public Health) is looking after alcohol control across Thailand. Obviously, it's unrealistic. The allocated resources to manage the (alcohol) problems are not proportionate to the extent of the problems.” - G2

“There will be gradual adjustments in terms of human and financial resources..., however the adjustments won’t be done abruptly.” - G1

\section{Credibility}

Besides the weak enforcement, light punitive measures and lax credibility of the law were believed to be a cause for the inefficiency of Thai alcohol control. The law allegedly failed to create deterrent effects. The respondents from academia and civil society sectors comparably noted that there was a lack of credibility of Thai law in general and urged a more rigorous attention of the government in the pursuit to reduce alcohol-related harm. The success of using strenuous enforcement to change people's smoking behaviour in Thailand was exemplified to be a suitable model for effective alcohol control. 
"why people avoid getting drunk (and drive) in Japan? Because they're afraid of being imprisoned. The law there is tough. The punishment like suspended sentence is not harsh enough,”- S1

'The reason (there seem to be more adverse impacts in Thailand) could be because of the lack of credibility of the law. Two things the law is useful for, one is to punish. Another is to create deterrent effects, deterring people from offending. The law in Thailand has no credibility, it can’t create deterrent effects” - A3

\section{Discussion:}

\section{Economic Availability}

This study finds that Thailand has not adequately and optimally utilised its alcohol control and relevant regulations to deter people from drinking and correspondingly achieve the optimal health outcomes. Firstly, alcohol taxation and pricing mechanisms are partially implemented. Despite available evidence confirming that alcohol tax and price levels are inversely associated to drinking level and encouraging the use of price mechanism to reduce alcohol consumption for public health benefits (Alexander C. Wagenaar et al., 2009), these benefits have not been well responded by the economic sector. The increases of alcohol excise tax have been inconsistent in frequency and are not proportionate to the economic dynamics such as the inflation rate. The tax rates are allegedly varied across different types of alcohol. This differential tax rate policy could be due to the alcohol industry's political interference on alcohol taxation system as noted in the previous alcohol tax adjustments (Bundit Sornpaisarn \& Kaewmungkun, 2014). The widely-discussed One-Plus-One taxation system is purportedly supported to be more efficient in excising alcoholic beverages. This is 
because not only the system would generate higher revenue, but the application of this system could also increase difficulty for alcohol producers to use condensing effect. The alcohol producers use the condensing effect by increasing the amount of ethanol in an alcoholic beverage to avoid paying higher excise tax resulting from specific tax (B. Sornpaisarn, Kaewmungkun, \& Rehm, 2015). Therefore, the system could increase the prices of low perceived-quality alcoholic beverages that prefer ad valorem taxation and the prices of high perceived-quality alcoholic beverages that prefer specific taxation. It should be noted that the excise taxation system, including of alcoholic beverages, was recently reformed in September 2017 (after the stakeholders interviews).

Besides taxation, the respondents also discussed the introduction of minimum pricing for alcoholic beverages in Thailand. As reported by a systematic review, the minimum pricing could reduce alcohol consumption in many other countries (Boniface et al., 2017). The minimum pricing increases the alcohol prices and exerts its diverse effects across household income quintiles, especially on the heavy drinkers (Vandenberg \& Sharma, 2016). At the present, research on pricing of alcoholic beverages in Thailand is minimal. Much of the research on the effects of minimum pricing is limited to provinces of Canada where some form of minimum pricing has been implemented and assessed to be significantly effective in reducing alcohol-related harm (Tim Stockwell et al., 2017; Thompson, Stockwell, Wettlaufer, Giesbrecht, \& Thomas, 2017). In Scotland, the Alcohol Minimum Pricing Act was passed in June 2012 and has attracted much national attention (T. Stockwell, 2014; The Scottish Government, 2017). However, its implementation has been delayed by alcohol industry’s legal challenge (The Scottish Government, 2017). Though, on 15 November 2017, the UK Supreme Court confirms that MUP can be lawfully introduced in Scotland and its introduction is expected to commence in May 2018. For Thailand, the probability of updating 
taxation and pricing policies will require substantial evidence to support the policy discussion and development. As previous research has found that the increased minimum prices were attributable to the reductions in alcohol-related traffic accidents (Tim Stockwell et al., 2017), which is one of desirable goals for Thailand.

To date, previous increases of alcohol tax rates are not known to be based on consultations with public health agency or other relevant sectors. Hence, the economic sector should work more collaboratively with relevant sectors and be able to demonstrate that any increase of alcohol tax adequately reflects the social costs of alcohol. Additionally, to make minimum pricing a politically feasible policy option, local data and research on the relationship between alcohol prices and alcohol-related harm are required to persuade policymakers and politicians to endorse their supports for such mechanism. Therefore, the control of economic availability of alcohol should be revised by incorporating the local data supported by strong political commitments and international success.

Nonetheless, despite evidence of the effectiveness of price-based alcohol policy interventions to reduce alcohol consumption and related harm (Boniface et al., 2017), as with most policies there are intended outputs and unintended consequences. An Australian study has recently found that low-income heavy drinkers could maintain their alcohol consumption levels, but spend less on other essentials (regressive effects), hence spending a larger proportion of income on alcohol due to MUP and increased taxes. Yet, these regressive effects are small and only concentrated among heavy drinkers. Furthermore, although the previous increase of excise taxes had reportedly little impacts on the level consumption of illegal white spirits in Thailand (Chaiyasong et al., 2011), raising alcohol taxes should consider the possible impacts on the consumption of unrecorded alcohol. This is because the consumption of unrecorded 
alcohol (illegal, smuggled, homebrewed, traditional alcohol), though age group-specific and diverse across the country (National Statistical Office, 2015), could also tremendously contribute to alcohol-related harm through many mechanisms (Rehm, Kanteres, \& Lachenmeier, 2010) and in turn impacts the formulation and outcomes of alcohol control policy (T. Thamarangsi, 2013). As these unintended possibilities could also happen in Thailand, the responsible authorities may have to tread carefully when there are economic decisions involving trade-offs.

\section{Physical Availability}

Among other factors, restriction on physical availability is an effective means of reducing alcohol-related harm locally (d'Abbs \& Togni, 2000; Toomey et al., 2012). This study found that the control of physical availability in Thailand is eminently deficient because of the excessive number of alcohol outlets. The findings are in line with the recent studies in Bangkok and peripheral area that found the $66 \%$ increase in density of alcohol outlets between 2009 and 2014 (Polpanatham, 2015). The study reported that there were as many as 97 alcohol outlets per square kilometre in Bangkok, and over 100 alcohol outlets within 500metre radius around universities in Bangkok and peripheral area. It is crucial for the Thai authorities to explore other alternatives to control the explosion of alcohol outlets to limit possible alcohol-related harm. This is significantly important because the previous research has found that the increase of alcohol outlet density could profoundly increase prevalence of binge drinking (Ahern et al., 2013). In addition, although, the alcohol-free zoning measure around tertiary educational institutions came into effect since October 2015, it is one of few measures that focuses on the physical availability. The use of inherent potential of city

planning, for example, should be explored to decrease the number of alcohol outlets. This is because the land use regulations have been found to be an effective public health advocacy tool to protect public health elsewhere (Ashe, Jernigan, Kline, \& Galaz, 2003). 
Other than effectively controlling the number and the physicality of alcohol outlets, the role of liquor licensing is necessary. Unlike a well-regarded liquor licensing practice such as in Scotland where licensing objectives aim to prevent crimes, promote public safety, and protect and improve public health (The Scottish Government, 2005), the public health perspective has not been considered for liquor licensing in Thailand, contributing to the proliferation of alcohol outlets. The licensing authority in Thailand is the Excise Department which is tasked with revenue generation, albeit being part of the Alcohol Control and Policy Committees. Because of these contradicting organisational visions and directions, it is important for Thailand to delineate its policy direction for liquor licensing for a better control of alcohol physical availability.

\section{Commercial Access}

Besides the control of supply side, the restrictions of commercial access to alcoholic beverages are challenging. The concerns of the noncompliance to the legal age and time restrictions for alcohol sales are in line with the findings of other experimental studies conducted in Thailand that assessed the compliance of off-premise outlets to the minimum purchasing age regulation. The studies have found that the off-premise retailers' compliance was extremely low (Puangsuwan, K., \& Thamarangsi, 2012). Only 0.1\% of all retailers requested the proof of age for alcohol purchases and merely one per cent of the retailers enquired about the purchasers' age. The success rate of underage alcohol purchase was 98.7\%. Again, the factors of the noncompliance could be due to the high number of alcohol

outlets (Chen et al., 2010; Rowland, Toumbourou, \& Livingston, 2015) and exacerbated by the lax government's surveillance and monitoring. Therefore, deterrence-based interventions like strenuous enforcement checks may be necessary and should be consistently conducted, 
because the enforcement checks, though have significant effects, could diminish over time (A. C. Wagenaar, Toomey, \& Erickson, 2005). Compliance-based interventions, such as compulsory alcohol risk management, responsible service of alcohol training, and independent compliance audit, should be introduced to supplement the deterrence-based interventions. Additionally, since the role of media in Thailand is paramount for societal changes in recent years and has contributed to the increased social awareness in diverse topics. The use of non-coercive measures, besides legal measures, could potentially increase compliance to alcohol regulations among retailers through social marketing intervention (Kamin \& Kokole, 2016) and be used as advocacy tool to promote public health and increase public support for health policies (Hilton, Wood, Patterson, \& Katikireddi, 2014). The expediency of the media advocacy could be strategically utilised to disseminate public health information, engage the local community's involvement, intensify collaborative works among government agencies and inspire policy development.

\section{Government Administration and Inter-organisational Interactions}

The effectiveness of alcohol control relies greatly on the integral roles of government agencies in both developing comprehensive regulations and implementing them efficiently and effectively. However, this study finds that the extent of inter-organisational interactions in the implementation phase is limited and fragmented. For Thailand, the probable cause for sub-optimal effectiveness of alcohol control may be due to the lacklustre collaboration between different government agencies. The public health stakeholders in this study repeatedly expressed their dissatisfaction with several issues, which non-public health government agencies are responsible for, such as the inconsistent increases of alcohol taxes and the excessive number of liquor licences. However, their interactions seem to be limited to compulsory periodic meetings as stipulated by the Thai Alcohol Control Act, while concrete 
integral efforts and consequently the mutual desired outcomes are obscure. Unlike, the integral efforts seen in the alcohol policy development phase in which the three interrelated sectors determinedly and simultaneously increased their roles in the regulatory development (Thaksaphon Thamarangsi, 2009). Hence, Thailand should increase its collaborative efforts in the implementation of alcohol-related measures to maximise the effectiveness of the hardfought alcohol policy. Furthermore, the resource mobilisation and allocation for alcohol control should reflect well on the size of the workload and the social costs of alcohol consumption.

\section{Future Directions of Thai Alcohol Policy}

As the control of alcohol and its associated problems are both supply and demand related. A comprehensive policy is required to effectively manage these alcohol-related problems. Although Thailand has been increasing its efforts to amalgamate the evidence-based strategies to reduce consumption and prevent drinking initiation in young people, there are rooms for improvement that require further considerations. Firstly, the supply reduction strategies should include substantial control of physical availability. These strategies may include strengthening procedures to obtain liquor licences including the introduction of compulsory responsible service of alcohol, enforcing extensive alcohol zoning areas, and involving government public health sector in licensing process. Secondly, although demand reduction strategies such as raising taxes deem to be preferable due to minimal costs involved in introducing such strategies, the previous increases were not well corresponding to the economic situation. The economic sector should involve other relevant sectors, though currently not obligated to, in the tax adjustment decisions to allow other sectors' reflections on related issues. Lastly, Thailand should actively enforce and implement harm reduction strategies that have been assessed to be effective such as random breath-testing of drivers and 
introduction of zero tolerance for young drivers. However, it is acknowledged that Thailand has yet to accept other harm reduction strategies due to surrounding controversies that are opposed to Thailand's abstinence standpoint. Ultimately, amalgamated efforts of different government agencies are encouraged, despite the obstacles due to different sets of law each government agency is obligated to and operating on. Ideally, inclusive Act may be required, which contain clauses that include, but not limited to, alcohol excise adjustment and pricing mechanism, liquor licensing, compliances to alcohol sale, and punishment for alcohol-related road traffic accidents.

\section{Limitations}

This study attempts to present the gaps in implementation and performance of regulations controlling alcohol availability and access in Thailand. However, there are two significant limitations that need to be addressed. First, since public health sector is the main actor in the development and implementation of alcohol policy, only the perspectives of key public health stakeholders were explored. Nevertheless, perspectives of other stakeholders, such as nonpublic health government agencies, businesses and consumers, though outside the scope of this research paper, are equally important for the optimal effects of the alcohol control regulations. The perspectives of these stakeholders should be explored in future research to provide supplementary insights and policy directions. Second, as discussed earlier, MUP and increase alcohol taxes are likely associated with other trade-offs such as regressive effects and the consumption of unrecorded alcohol. The study acknowledges the possible implications of increased alcohol taxes on the level of consumption of unrecorded alcohol, as stated in the abovementioned. However, the issue was little discussed in the interviews and is one of the limitations of the study. Nevertheless, since policy dialogue is known to be difficult to establish, this study provides a significance insights into gaps in availability and 
access regulations and pinpoints potential venues for future policy development and research, which are the strengths of this study.

\section{Conclusions:}

The use of alcohol is becoming ingrained in Thai society. This study demonstrates, environmental influences of alcohol play a pivotal role in inducing drinking behaviour. Strenuous implementation of statutory regulations in the interests of public health is needed. Improving alcohol pricing and taxation, restricting the numbers and physicality of alcohol outlets, better monitoring of alcohol sales to minors, and introducing responsible service of alcohol training could strengthen alcohol control in Thailand. Furthermore, the lack of robustness of enforcement and disintegration of governmental organisations in regulating availability and access have created niche environment for normalising alcohol consumption. Other relevant non-public health stakeholders ought to increase their roles to support public health sector to achieve the optimum results from the hard-fought alcohol policy.

\section{Acknowledgements:}

This research has been conducted with the support of the Australian Government Research Training Program Scholarship. We are very grateful to the respondents who kindly contributed to the study. This work was carried out with funding from University of Wollongong School of Health and Society and the Centre for Alcohol Studies, Thai Health Promotion Foundation, and with support from the Global Health Division, Ministry of Public Health, Thailand. The funding bodies had no role in study design, analysis, decision to publish, or preparation of the manuscript. 
Conflicts of interest: None

\section{References:}

Ahern, J., Margerison-Zilko, C., Hubbard, A., \& Galea, S. (2013). Alcohol outlets and binge drinking in urban neighborhoods: the implications of nonlinearity for intervention and policy. Am J Public Health, 103(4), e81-87. doi:10.2105/ajph.2012.301203

Ashe, M., Jernigan, D., Kline, R., \& Galaz, R. (2003). Land use planning and the control of alcohol, tobacco, firearms, and fast food restaurants. Am J Public Health, 93(9), 14041408.

Assanangkornchai, S., Mukthong, A., \& Intanont, T. (2009). Prevalence and patterns of alcohol consumption and health-risk behaviors among high school students in Thailand. Alcohol Clin Exp Res, 33(12), 2037-2046. doi:10.1111/j.15300277.2009.01043.x

Boniface, S., Scannell, J. W., \& Marlow, S. (2017). Evidence for the effectiveness of minimum pricing of alcohol: a systematic review and assessment using the Bradford Hill criteria for causality. BMJ Open, 7(5), e013497. doi:10.1136/bmjopen-2016013497

Callaghan, R. C., Sanches, M., \& Gatley, J. M. (2013). Impacts of the minimum legal drinking age legislation on in-patient morbidity in Canada, 1997-2007: a regressiondiscontinuity approach. Addiction, 108(9), 1590-1600. doi:10.1111/add.12201

Callaghan, R. C., Sanches, M., Gatley, J. M., \& Cunningham, J. K. (2013). Effects of the minimum legal drinking age on alcohol-related health service use in hospital settings in Ontario: a regression-discontinuity approach. Am J Public Health, 103(12), 22842291. doi:10.2105/ajph.2013.301320

Callaghan, R. C., Sanches, M., Gatley, J. M., \& Stockwell, T. (2014). Impacts of drinkingage laws on mortality in Canada, 1980-2009. Drug Alcohol Depend, 138, 137-145. doi:10.1016/j.drugalcdep.2014.02.019

Chaiyasong, S., Limwattananon, S., Limwattananon, C., Thamarangsi, T., Tangchareonsathien, V., \& Schommer, J. (2011). Impacts of excise tax raise on illegal and total alcohol consumption: A Thai experience. Drugs: Education, Prevention and Policy, 18(2), 90-99. doi:10.3109/09687637.2010.484451

Chaveepojnkamjorn, W., \& Pichainarong, N. (2011). Current drinking and health-risk behaviors among male high school students in central Thailand. BMC Public Health, 11, 233-233. doi:10.1186/1471-2458-11-233

Chen, M. J., Grube, J. W., \& Gruenewald, P. J. (2010). Community alcohol outlet density and underage drinking. Addiction, 105(2), 270-278. doi:10.1111/j.13600443.2009.02772.X

d'Abbs, P., \& Togni, S. (2000). Liquor licensing and community action in regional and remote Australia: a review of recent initiatives. Aust N Z J Public Health, 24(1), 4553.

Duke, A. A., Giancola, P. R., Morris, D. H., Holt, J. C., \& Gunn, R. L. (2011). Alcohol dose and aggression: another reason why drinking more is a bad idea. $J$ Stud Alcohol Drugs, 72(1), 34-43. 
Grubesic, T. H., Pridemore, W. A., Williams, D. A., \& Philip-Tabb, L. (2013). Alcohol outlet density and violence: the role of risky retailers and alcohol-related expenditures. Alcohol Alcohol, 48(5), 613-619. doi:10.1093/alcalc/agt055

Hilton, S., Wood, K., Patterson, C., \& Katikireddi, S. V. (2014). Implications for alcohol minimum unit pricing advocacy: What can we learn for public health from UK newsprint coverage of key claim-makers in the policy debate? Social Science \& Medicine, 102, 157-164. doi:http://dx.doi.org/10.1016/j.socscimed.2013.11.041

Kamin, T., \& Kokole, D. (2016). Midstream social marketing intervention to influence retailers' compliance with the minimum legal drinking age law. Journal of Social Marketing, 6(2), 104-120. doi:10.1108/JSOCM-05-2015-0030

Meier, P. S., Holmes, J., Angus, C., Ally, A. K., Meng, Y., \& Brennan, A. (2016). Estimated Effects of Different Alcohol Taxation and Price Policies on Health Inequalities: A Mathematical Modelling Study. PLoS Med, 13(2), e1001963. doi:10.1371/journal.pmed.1001963

National Statistical Office. (2015). The Smoking and Drinking Behaviour Survey 2014 Report. Retrieved from

Polpanatham, P. (2015). Dispersion of Alcohol Outlets Around Universities in Bangkok and Peripheral Areas.

Puangsuwan, A., K., P., \& Thamarangsi, T. (2012). Law Compliance of Off-Premise Alcohol Retailers on Minimum Purchase Age Restriction. Retrieved from www.cas.or.th

Rehm, J., Kanteres, F., \& Lachenmeier, D. W. (2010). Unrecorded consumption, quality of alcohol and health consequences. Drug Alcohol Rev, 29(4), 426-436. doi:10.1111/j.1465-3362.2009.00140.x

Rowland, B., Toumbourou, J. W., \& Livingston, M. (2015). The association of alcohol outlet density with illegal underage adolescent purchasing of alcohol. J Adolesc Health, 56(2), 146-152. doi:10.1016/j.jadohealth.2014.08.005

Rowland, B., Toumbourou, J. W., Satyen, L., Tooley, G., Hall, J., Livingston, M., \& Williams, J. (2014). Associations between alcohol outlet densities and adolescent alcohol consumption: a study in Australian students. Addict Behav, 39(1), 282-288. doi:10.1016/j.addbeh.2013.10.001

Royal Thai Government Gazette. (2008). Alcoholic Beverage Control Act B.E. 2551. The Secretariat of The Cabinet Retrieved from www.mratchakitcha.soc.go.th/.

Sornpaisarn, B., \& Kaewmungkun, C. (2014). Politics of alcohol taxation system in Thailand: behaviours of three major alcohol companies from 1992 to 2012. International Journal Of Alcohol And Drug Research, 3(3), 9. doi:10.7895/ijadr.v3i3.155

Sornpaisarn, B., Kaewmungkun, C., \& Rehm, J. (2015). Assessing Patterns of Alcohol Taxes Produced by Various Types of Excise Tax Methods--A Simulation Study. Alcohol Alcohol, 50(6), 639-646. doi:10.1093/alcalc/agv065

Sornpaisarn, B., Shield, K. D., Österberg, E., \& Rehm, J. (Eds.). (2017). Resource tool on alcohol taxation and pricing policies. Geneva: World Health Organization.

Stockwell, T. (2014). Minimum unit pricing for alcohol. Bmj, 349, g5617. doi:10.1136/bmj.g5617

Stockwell, T., Zhao, J., Sherk, A., Callaghan, R. C., Macdonald, S., \& Gatley, J. (2017). Assessing the impacts of Saskatchewan's minimum alcohol pricing regulations on alcohol-related crime. Drug Alcohol Rev, 36(4), 492-501. doi:10.1111/dar.12471

Thamarangsi, T. (2009). The "Triangle That Moves the Mountain" and Thai Alcohol Policy Development: Four Case Studies. Contemporary Drug Problems, 36(1-2), 245-281. doi:10.1177/009145090903600112

Thamarangsi, T. (2013). Unrecorded alcohol: significant neglected challenges. Addiction, 108(12), 2048-2050. doi:10.1111/add.12300 
The Scottish Government. (2005). Licensing (Scotland) Act 2005. Edinburgh: The National Archives, UK Retrieved from https://www.legislation.gov.uk/asp/2005/16/contents.

The Scottish Government. (2017, 9 March 2017). Minimum Unit Pricing. Retrieved from http://www.gov.scot/Topics/Health/Services/Alcohol/minimum-pricing

Thompson, K., Stockwell, T., Wettlaufer, A., Giesbrecht, N., \& Thomas, G. (2017). Minimum alcohol pricing policies in practice: A critical examination of implementation in Canada. J Public Health Policy, 38(1), 39-57. doi:10.1057/s41271016-0051-y

Toomey, T. L., Erickson, D. J., Carlin, B. P., Quick, H. S., Harwood, E. M., Lenk, K. M., \& Ecklund, A. M. (2012). Is the density of alcohol establishments related to nonviolent crime? J Stud Alcohol Drugs, 73(1), 21-25.

Vandenberg, B., \& Sharma, A. (2016). Are Alcohol Taxation and Pricing Policies Regressive? Product-Level Effects of a Specific Tax and a Minimum Unit Price for Alcohol. Alcohol and Alcoholism, 51(4), 493-502. doi:10.1093/alcalc/agv133

Wagenaar, A. C., Salois, M. J., \& Komro, K. A. (2009). Effects of beverage alcohol price and tax levels on drinking: a meta-analysis of 1003 estimates from 112 studies. Addiction, 104(2), 179-190. doi:10.1111/j.1360-0443.2008.02438.x

Wagenaar, A. C., Toomey, T. L., \& Erickson, D. J. (2005). Complying with the minimum drinking age: effects of enforcement and training interventions. Alcohol Clin Exp Res, 29(2), 255-262.

Wicki, M., Kuntsche, E., \& Gmel, G. (2010). Drinking at European universities? A review of students' alcohol use. Addict Behav, 35(11), 913-924. doi:10.1016/j.addbeh.2010.06.015

World Health Organization. (2010). Global strategy to reduce the harmful use of alcohol. In: World Health Organization.

World Health Organization. (2011). Addressing the harmful use of alcohol: A guide to developing effecitve regislation. Retrieved from

World Health Organization. (2014). Global status report on alcohol and health 2014. Retrieved from Luxembourg:

Xuan, Z., Nelson, T. F., Heeren, T., Blanchette, J., Nelson, D. E., Gruenewald, P., \& Naimi, T. S. (2013). Tax policy, adult binge drinking, and youth alcohol consumption in the United States. Alcohol Clin Exp Res, 37(10), 1713-1719. doi:10.1111/acer.12152 